\title{
Influence of preparation method on the performance of vanadia-niobia catalysts for the oxidative dehydrogenation of propane
}

\author{
R.H.H. Smits, K. Seshan, H. Leemreize and J.R.H. Ross' \\ Faculty of Chemical Technology, University of Twente, P.O. Box 217, 7500 AE \\ Enschede, The Netherlands
}

\begin{abstract}
The influence of various preparation methods on the performance of $\mathrm{V}-\mathrm{Nb}-\mathrm{O}$ catalysts has been investigated. It was found that the activity and selectivity of a vanadium site depend on the nature of the neighbouring atoms. Vanadium neighbours provide activity, while niobium neighbours provide selectivity. Careful preparation of these catalysts ensures a homogeneous distribution and good mixing of the vanadium and niobium. It was also found that the vanadium becomes mobile upon reduction and this results in better distribution of vanadium in used catalysts.
\end{abstract}

\section{INTRODUCTION}

There is currently an increasing interest in the catalytic activation of lower alkanes. Following the initial work of Chaar et al. [1] on the oxidative dehydrogenation of n-butane, a number of papers have appeared on the oxidative dehydrogenation of propane and butane [2-12], over V-Mg-O catalysts. Propane is usually investigated because the oxidative dehydrogenation of this molecule may be an attractive alternative route compared to conventional dehydrogenation and cracking for the production of propylene. Oxidative dehydrogenation of isobutane is another interesting application as the isobutylene produced could be used in the synthesis of MTBE. Research on $\mathrm{V}-\mathrm{Mg}-\mathrm{O}$ catalysts has focused on discussions of the nature of the active phase: magnesium orthovanadate or pyrovanadate $[1,8,9]$. In a recent paper [7], Kung et al. claimed that both orthovanadate and pyrovanadate are selective for oxidative dehydrogenation of propane but only magnesium orthovanadate is selective in the oxidative dehydrogenation of butane. The contamination with potassium caused by the preparation method used by Siew Hew Sam et al. $[8,9]$ resulted in a less selective catalyst.

'Present address: University of Limerick, Plassey Technological Park, Limerick, Ireland. 
We have attempted to improve the $\mathrm{V}-\mathrm{Mg}-\mathrm{O}$ catalyst system by doping it with various elements $[12,13]$, but these attempts were not successful. We have therefore focused our attention on niobium pentoxide for the following reasons:

- niobium is in the same group of the periodic table as vanadium, and is expected to have similar properties.

- niobium is much more difficult to reduce than vanadium (easy reduction often causes low selectivity in selective oxidation reactions).

- it had been previously shown, for example, that the addition of niobium oxide to a mixture of molybdenum and vanadium oxides improves the activity of this system for the oxidative dehydrogenation of ethane [14].

We have shown in previous papers $[15,16]$ that high selectivities towards propylene were possible using pure niobia, but that the conversions were low.

We have recently presented the results of experiments which show that the activity of niobia can be improved considerably, while maintaining high selectivity, by adding other suitable elements such as vanadium, chromium and molybdenum [17]. Vanadium appeared to be the most beneficial. In the same publication, we have also presented some results obtained with vanadium containing catalysts prepared by different methods. In the present paper, we present the results of a more detailed and systematic investigation of the infiuence of preparation methods on the performance of $\mathrm{V}-\mathrm{Nb}-\mathrm{O}$ catalysts.

\section{EXPERIMENTAL}

\subsection{Catalyst Preparation}

Series 1. The first group of catalysts examined was made by evaporation of the water from an oxalic acid solution of the oxalate salts of niobium and vanadium, chromium or molybdenum using a rotary evaporator. For the catalysts containing vanadium ions, the amount of vanadium added was varied. $\mathrm{A} 10 \mathrm{wt} \% \mathrm{~V}_{2} \mathrm{O}_{5} / \mathrm{MgO}$ catalyst was prepared by aqueous wet impregnation of an appropriate of ammonium metavanadate onto a $\mathrm{MgO}$ support $\left(50 \mathrm{~m}^{2} / \mathrm{g}\right)$, followed by calcination at $580^{\circ} \mathrm{C}$ for $3 \mathrm{~h}$. An undoped niobium oxide catalyst was made by calcination of hydrated niobia at $650^{\circ} \mathrm{C}$ for $5 \mathrm{~h} \mathrm{[17].}$

Series II. From the results obtained for the Series I catalysts, it was found that the method of preparation could influence the performance of the catalyst (see reference [17] and Table 2). Samples containing 1 mol\% $\mathrm{V}_{2} \mathrm{O}_{5}$ were found to be especially sensitive to the method of preparation used. A second group of catalysts containing approx. 1 mol\% $\mathrm{V}_{2} \mathrm{O}_{5}$ in $\mathrm{Nb}_{2} \mathrm{O}_{5}$ was therefore prepared, using four different methods. The first of these was prepared by adsorption of vanadyl acetyl acetonate $\left(\mathrm{VO}(\mathrm{ACAC})_{2}\right)$ from a toluene solution; the amount of $\mathrm{VO}(\mathrm{AcAc})_{2}$ used was equivalent to 4 mol\% $\mathrm{V}_{2} \mathrm{O}_{5}$ or one monolayer and the support was prepared from hydrated niobia (Niobium Products Company batch $\mathrm{AD} / 628$ ) by calcination at $500^{\circ} \mathrm{C}$ for $5 \mathrm{~h}$ (BET surface area $34.3 \mathrm{~m}^{2} / \mathrm{g}$ ). The same support was used for the preparation of the second sample; this 
involved wet impregnation using an aqueous solution of $\mathrm{NH}_{4} \mathrm{VO}_{3}$, followed by evaporation of the solvent. The third sample was made by coprecipitation from a mixed oxalic acid solution of niobium and vanadium using aqueous ammonia. The $\mathrm{pH}$ of precipitation was maintained automatically at 9 (it was difficult to control the $\mathrm{pH}$ at the start of the preparation due to oversaturation of the solution, and the resulting suspension was difficult to filter on a glass filter). The fourth sample was prepared using the "melt" method. A mixture of $0.07 \mathrm{~g} \mathrm{NH}_{4} \mathrm{VO}_{3}, 10 \mathrm{~g}$ hydrated niobia and $40 \mathrm{~g}$ oxalic acid dihydrate was heated to $120^{\circ} \mathrm{C}$ in static air. The oxalic acid dissolved in its own water of crystallisation and the vanadium and niobium dissolved partially. After overnight heating, the excess oxalic acid of this slurry had evaporated and the oxalates had decomposed partially, this resulting in a fine powder. The dried powders were calcined $5 \mathrm{~h}$ at $630^{\circ} \mathrm{C}$ in static air.

Series III. In order to investigate the effect of various variables on the properties of the final catalysts prepared by the melt method described above, a third series of catalysts was prepared in which a number of these parameters were varied. These included the temperature of evaporation, the rate of flow of air during both evaporation and the final heating step ( $3 \mathrm{~h}$ at $250^{\circ} \mathrm{C}$ ), and the amount of oxalic acid added. The amount of vanadium added was equivalent to $1 \mathrm{~mol} \%$ in all cases. The parameters varied in each catalyst preparation are summarised in Table 1. The standard procedure (sample A) involved the following steps: heating a mixture of $0.07 \mathrm{~g} \mathrm{NH}_{4} \vee \mathrm{O}_{3}, 10 \mathrm{~g}$ hydrated niobia and $40 \mathrm{~g}$ oxalic acid dihydrate in a tube furnace at $130^{\circ} \mathrm{C}$ for $10 \mathrm{~h}$, followed by $3 \mathrm{~h}$ at $250^{\circ} \mathrm{C}$ in flowing air $\left(5 \mathrm{dm}^{3} \mathrm{~min}^{-1}\right)$. All the resultant powders were calcined at $630^{\circ} \mathrm{C}$ for $5 \mathrm{~h}$ before use.

Table 1

Parameters varied in the preparation of catalysts using the melt method

\begin{tabular}{cccc}
$\begin{array}{c}\text { Sample } \\
\text { Evaporation } \\
\text { temp }\left({ }^{\circ} \mathrm{C}\right)\end{array}$ & $\begin{array}{c}\text { Oxalic acid } \\
\text { added }(\mathrm{g})\end{array}$ & $\begin{array}{c}\text { Evaporation air } \\
\text { flow }(1 / \mathrm{min})\end{array}$ & $\begin{array}{c}\text { Decomposition } \\
\text { air flow }(1 / \mathrm{min})\end{array}$ \\
\hline
\end{tabular}

\begin{tabular}{lcccc} 
A & 130 & 40 & 5 & 5 \\
B & 130 & 40 & 10 & 10 \\
C & 130 & 80 & 5 & 5 \\
D & 100 & 40 & 5 & 5 \\
E & b & 80 & 0 & 0 \\
F & 120 & 40 & 5 & 0 \\
G & 160 & 40 & 5 & 0 \\
\hline
\end{tabular}

a before calcination, ${ }^{b}$ evaporated from a beaker immersed in an oil bath at $165^{\circ} \mathrm{C}$

Series IV. To investigate the influence of the calcination temperature on the performance of the final catalysts of Series III, a powder was prepared from $0.14 \mathrm{~g}$ $\mathrm{NH}_{4} \mathrm{VO}_{3}, 20 \mathrm{~g}$ hydrated niobia and $80 \mathrm{~g}$ oxalic acid dihydrate $(1 \mathrm{~mol} \% \mathrm{~V}$ in the final 
catalyst) in a way similar to that described in the previous paragraph. The mixture was heated to $140^{\circ} \mathrm{C}$ for $10 \mathrm{~h}$, after which it was treated at $300^{\circ} \mathrm{C}$ for a further $2 \mathrm{~h}$. An air flow of approx. $8 \mathrm{dm}^{3} / \mathrm{min}$. was used. The resulting powder was split into five parts, and these were calcined for $5 \mathrm{~h}$ at $550{ }^{\circ} \mathrm{C}, 600^{\circ} \mathrm{C}, 650^{\circ} \mathrm{C}, 700^{\circ} \mathrm{C}$ and $750{ }^{\circ} \mathrm{C}$, respectively.

\subsection{Catalyst Characterisation}

The catalysts (600 mg 0.3-0.6 mm grains) were tested for catalytic activity using a flow reactor system which has been described previously [16]. The gas feed consisted of 10 vol\% $\mathrm{O}_{2}, 30$ vol\% $\mathrm{C}_{3} \mathrm{H}_{8}$ and 60 vol\% $\mathrm{He}$, with a total flow of $140 \mathrm{~cm}^{3} / \mathrm{min}$. In each test the sample was heated in a series of seven steps of $25^{\circ} \mathrm{C}$ in the required temperature range, and a sequence of analyses was made during each temperature step; each temperature was maintained for two hours. Two or more temperature cycles were made with each catalyst sample; the results of the first cycle will be referred to as applying to "fresh catalyst", and those of the second cycle to "used catalyst".

The catalysts were characterised before and after use by BET surface area measurement using $\mathrm{N}_{2}$ adsorption. The overall chemical composition was determined by XRF, while XPS was used for the determination of the surface composition of several selected samples (using a Kratos XSAM 800). The concentration of vanadium was calculated from the corrected XPS peak areas of the Nb3d and V2 $p^{3 / 2}$ signals; due to interference of the O1s satellite peak with the V2p peak, the limit of error in the vanadium concentration was estimated to be $\pm 10 \%$.

\section{RESULTS AND DISCUSSION}

\subsection{Pure and modified niobia}

The results of the characterisation and catalyst testing of catalysts of Series I (pure and modified niobia) are displayed in Table 2. Results obtained from a V-Mg-O catalyst are included for comparison. The rates of conversion of propane are calculated from the integral conversions. These conversions were taken from the data obtained at temperatures at which oxygen conversion was less than $20 \%$. The results shown in this table have been discussed in more detail in a previous paper [17], while more results on the influence of the amount of vanadium added will be published later [18]. It is clear that the performance of the vanadium-doped niobium oxide catalysts were superior to those of the other catalysts shown in this table; a possible exception was the chromium-doped catalysts which showed higher selectivities but the temperature was lower because of its high activity. This has been the basis of further work with $V$ $\mathrm{Nb}-\mathrm{O}$ catalysts as discussed in this paper. It can also be seen from this table that a low loading of vanadium ( $1 \mathrm{~mol} \%$ ) is sufficient to give an active and selective catalyst. Studies presented in this paper will hence be limited to catalysts containing $1 \mathrm{~mol} \%$ vanadium. 
Table 2

Results of XRF, BET surface area measurement and catalytic testing for catalysts of the first group.

\begin{tabular}{|c|c|c|c|c|c|}
\hline Sample & $\begin{array}{l}\text { Amount } \\
\left(\mathrm{mol} \%{ }^{\mathrm{a}}\right)\end{array}$ & $\begin{array}{c}\text { Surface area } \\
\left(\mathrm{m}^{2} / \mathrm{g}\right)\end{array}$ & $\begin{array}{c}\text { Rate at } 350^{\circ} \mathrm{C} \\
\left(\mu \mathrm{mol} / \mathrm{m}^{2} . \mathrm{s}\right)\end{array}$ & $\begin{array}{l}\text { Temperature } \\
\text { (for/at } 20 \% \mathrm{O}_{2}\end{array}$ & $\begin{array}{l}\text { Selectivity } \\
\text { conversion) }\end{array}$ \\
\hline $\mathrm{V}-\mathrm{Mg}-\mathrm{O}$ & 4.6 & 48 & - & 419 & 60 \\
\hline $\mathrm{Nb}_{2} \mathrm{O}_{5}$ & 0 & 9.9 & - & 581 & 72 \\
\hline Mo5Nb & nd & 15.7 & - & 498 & 88 \\
\hline Cr5Nb & 4.3 & 43.2 & 1.4 & 372 & 78 \\
\hline V0.25Nb & 0.26 & 11.0 & - & 565 & 77 \\
\hline $\mathrm{V} 1 \mathrm{Nb}$ & 0.93 & 33.2 & 2.0 & 423 & 77 \\
\hline VINb & 0.99 & $16.1^{b}$ & 4.6 & 423 & 76 \\
\hline V5Nb & 4.58 & 11.3 & 8.6 & 390 & 70 \\
\hline V10Nb & 8.64 & 9.4 & 10.3 & 408 & 75 \\
\hline
\end{tabular}

a element added relative to $\mathrm{Nb}$ or $\mathrm{Mg},{ }^{\mathrm{b}}$ the lower surface area is caused by a slightly different way of preparation

\subsection{Catalysts prepared via different methods}

The results of the characterisation and catalytic testing of the second group of catalysts (prepared via different methods) are shown in Table 3 . The rates given per $\mathrm{m}^{2}$ of $\mathrm{V}$ shown in this table were calculated by dividing the integral rate of propane consumption per unit area by the surface fraction of vanadium calculated from the results of XPS. These values are equivalent to turnover numbers.

The results in Table 3 indicate that although the catalysts have widely different activities per gram catalyst, the activity per vanadium concentrated in the surface, is more or less constant. This leads to the suggestion that activation of propane takes place on a vanadium site at the surface. The selectivities of the various catalysts are different, however, and this implies that not all the sites at the surface are similar in nature. The values of the BET surface areas of the catalysts prepared by the coprecipitation and melt methods decreased to approximately half the original values; however, the areas of the catalysts prepared by adsorption and impregnation decreased only slightly. The differences between the catalysts have thus become smaller. The selectivities towards propylene have increased, while the activities per gram of catalyst decreased. The impregnation catalyst shows an exceptional behaviour. It did not lose much of its activity, while the selectivity improved more than with the other catalysts. In contrast to the other catalysts, this catalyst did not at any stage in the tests give $100 \%$ oxygen conversion. The fact that the catalyst has reached $100 \%$ oxygen conversion is important with respect to the possibility of the catalyst being reduced. This will be discussed in detail later. The rate of propane consumption per $\mathrm{m}^{2}$ vanadium on the used coprecipitation catalyst is similar to the rates obtained on the fresh catalysts, suggesting that the deactivation observed is mainly caused by 
changes in the surface area and of the vanadium availability on the catalysts surface.

Table 3

Results of characterisation and catalytic testing of catalysts prepared by four different methods.

Preparation Conc. V (mol\%) BET area Rate of propane consumption ${ }^{\mathbf{a}}$ Selectivity method Total Surface $\left(\mathrm{m}^{2} / \mathrm{g}\right) \quad(\mu \mathrm{mol} / \mathrm{g} . \mathrm{s}) \quad\left(\mu \mathrm{mol} / \mathrm{m}^{2} . \mathrm{s}\right)\left(\mu \mathrm{mol} / \mathrm{m}^{2} \mathrm{~V} . \mathrm{s}\right)$

\begin{tabular}{|c|c|c|c|c|c|c|c|}
\hline \multicolumn{8}{|l|}{ Adsorption } \\
\hline Adsorption & 215 & 126 & 190 & $356^{c}$ & $179^{c}$ & $142^{c}$ & 612 \\
\hline used & 2.10 & 12.0 & 19.9 & 30.0 & $150^{\circ}$ & 14.2 & 01.2 \\
\hline \multicolumn{8}{|c|}{ Impregnation } \\
\hline fresh & 1.22 & 8.5 & 19.1 & $17.0^{\mathrm{c}}$ & $0.89^{c}$ & $10.5^{c}$ & 50.7 \\
\hline used & nd & nd & 15.8 & $15.1^{c}$ & $0.95^{c}$ & nd & 58.9 \\
\hline \multicolumn{8}{|c|}{ Coprecipitation } \\
\hline fresh & 1.09 & 4.6 & 27.8 & 15.7 & 0.56 & 12.3 & 69.3 \\
\hline used & nd & 6.9 & 13.8 & 9.6 & 0.70 & 10.1 & 73.0 \\
\hline \multicolumn{8}{|l|}{ Melt } \\
\hline fresh & 1.01 & 2.6 & 38.6 & 15.0 & 0.39 & 14.9 & 65.9 \\
\hline used & nd & nd & 19.0 & 8.9 & 0.47 & nd & 70.0 \\
\hline
\end{tabular}

a at $400{ }^{\circ} \mathrm{C},{ }^{b}$ at $50 \%$ oxygen conversion, ${ }^{c} 200 \mathrm{mg}$ of catalyst and $400 \mathrm{mg}$ quartz were used.

\subsection{Catalysts prepared via the melt method}

Table 4 shows the results obtained for the Series III catalysts. The reaction rates of the fresh catalysts per gram of catalyst are widely different but the activities per unit surface area are similar. Only the activity of sample D is lower; this sample also has the highest surface area. After use, the rates per unit surface area of almost all the samples had decreased, and the values are similar to each other. There is a correlation between the loss in activity (per gram catalyst) and the oxygen conversion reached; a catalyst appears to deactivate more when it has been at lower oxygen concentrations (conversion of oxygen). This correlation was confirmed by testing sample $D$ at a lower series of temperatures, so that $\leq 70 \%$ oxygen conversion was reached. The catalyst lost only $24 \%$ of its original activity. No further deactivation was observed when the catalyst was tested in three more temperature cycles taking care that the maximum oxygen conversion was always $\leq 70 \%$. The apparent activation energy measured for the fresh catalysts was generally lower than that for the used catalysts. A possible explanation is that the fresh catalysts deactivate during the experiments; with every increase in the temperature there is an increase in reaction rate, but this is not as great as would be predicted from the activation energy without simultaneous deactivation, this leading to a lower apparent activation energy. In agreement with this suggestion is the observation that the lowest apparent activation energies calculated for the fresh 
catalysts were found for those materials which deactivated the most. The average apparent activation energy of the used catalysts $(104 \mathrm{~kJ} / \mathrm{mol})$ is closer to the true value. The activation energy found here is smaller than that found by Patel et al., who found a value for propane activation over $40 \mathrm{wt} \% \mathrm{~V}_{2} \mathrm{O}_{5} / \mathrm{MgO}$ of $142 \mathrm{~kJ} / \mathrm{mol}$ [3].

The selectivities obtained show little variation, with slightly higher selectivities obtained for the samples having a low surface area. The selectivities after use are often slightly higher.

Table 4

Results of characterisation and catalytic testing for catalysts prepared by modifications of the melt method

Sample BET area Rate at $394^{\circ} \mathrm{C}$ Apparent $\mathrm{E}_{\mathrm{a}}$ Selectivity ${ }^{\mathrm{a}}$ Max. $\mathrm{O}_{2}$-conv./ $\left(\mathrm{m}^{2} / \mathrm{g}\right) \quad(\mu \mathrm{mol} / \mathrm{g} . \mathrm{s})\left(\mu \mathrm{mol} / \mathrm{m}^{2} . \mathrm{s}\right) \quad(\mathrm{kJ} / \mathrm{mol}) \quad$ Loss in activity $^{\mathrm{b}}$

\begin{tabular}{|c|c|c|c|c|c|c|c|}
\hline \multirow[t]{2}{*}{ A } & fresh & 3.3 & 2.8 & 0.84 & 89.4 & 87.9 & 29 \\
\hline & used & 4.4 & 2.4 & 0.54 & 101.1 & 88.0 & 15 \\
\hline \multirow[t]{2}{*}{ B } & fresh & 6.0 & 5.2 & 0.87 & 77.4 & 86.2 & 70 \\
\hline & used & 6.5 & 3.5 & 0.53 & 103.1 & 86.5 & 33 \\
\hline \multirow[t]{2}{*}{ C } & fresh & 3.2 & 3.3 & 1.04 & 86.1 & 87.5 & 37 \\
\hline & used & 3.7 & 2.7 & 0.73 & 98.8 & 87.6 & 18 \\
\hline \multirow[t]{2}{*}{ D } & fresh & 16.2 & 8.3 & 0.51 & 85.7 & 82.1 & 100 \\
\hline & used & 10.4 & 4.7 & 0.73 & 108.2 & 83.9 & 44 \\
\hline \multirow[t]{2}{*}{$E$} & fresh & 3.0 & 3.2 & 1.08 & 86.3 & 90.0 & 60 \\
\hline & used & 4.2 & 2.7 & 0.65 & 98.3 & 87.6 & 16 \\
\hline \multirow[t]{2}{*}{$F$} & fresh & 10.2 & 10.4 & 1.02 & 80.9 & 83.1 & 100 \\
\hline & used & 9.0 & 5.0 & 0.55 & 109.7 & 84.8 & 52 \\
\hline \multirow[t]{2}{*}{$\mathbf{G}$} & fresh & 8.0 & 8.1 & 1.01 & 71.7 & 84.2 & 100 \\
\hline & used & 7.5 & 3.8 & 0.51 & 101.3 & 85.7 & 53 \\
\hline
\end{tabular}

a at $20 \%$ oxygen conversion, ${ }^{b}$ rate over fresh catalyst/rate over used catalyst ${ }^{*} 100 \%$ (per gram catalyst)

\subsection{Catalysts calcined at different temperatures}

Results obtained for 1 mol\% $\mathrm{V}_{2} \mathrm{O}_{5} / \mathrm{Nb}_{2} \mathrm{O}_{5}$ catalysts which were calcined at different temperatures are shown in Table 5. XRD showed that an additional phase $\left(\mathrm{NNb}_{9} \mathrm{O}_{25}\right)$ was present in the sample calcined at $750^{\circ} \mathrm{C}$. This phase was observed by us previously only in samples containing more than 5 mol\% $\mathrm{V}_{2} \mathrm{O}_{5}(\mathrm{~V} 5 \mathrm{Nb}$ and $\mathrm{V} 10 \mathrm{Nb}$ in table 1, [17]). Except for the sample calcined at $550^{\circ} \mathrm{C}$, the specific activity slowly increases with increasing calcination temperature; however when the new phase was formed at $750^{\circ} \mathrm{C}$ the specific activity decreased. It thus seems that the mixed oxide phase is less active for the activation of propane. 
Table 5

Surface areas and reaction rates of catalysts containing $1 \mathrm{~mol} \% \mathrm{~V}_{2} \mathrm{O}_{5}$ calcined at different temperatures.

\begin{tabular}{lccc}
$\begin{array}{l}\text { Calcination } \\
\text { temperature }\left({ }^{\circ} \mathrm{C}\right)\end{array}$ & $\begin{array}{c}\text { Phases } \\
\text { present }\end{array}$ & $\begin{array}{c}\text { BET surface } \\
\text { area }\left(\mathrm{m}^{2} / \mathrm{g}\right)\end{array}$ & $\begin{array}{c}\text { Rate at } 400{ }^{\circ} \mathrm{C} \\
\left(\mu \mathrm{mol} / \mathrm{m}^{2} . \mathrm{s}\right)\end{array}$ \\
\hline 550 & $\mathrm{TT}-\mathrm{Nb}_{2} \mathrm{O}_{5}$ & 35.2 & 0.37 \\
600 & $\mathrm{~T}-\mathrm{Nb}_{2} \mathrm{O}_{5}$ & 9.7 & 0.75 \\
650 & $\mathrm{~T}^{-\mathrm{Nb}_{2} \mathrm{O}_{5}}$ & 6.0 & 0.81 \\
700 & $\mathrm{~T}-\mathrm{Nb}_{2} \mathrm{O}_{5}$ & 4.5 & 0.94 \\
750 & $\mathrm{~T}-\mathrm{Nb}_{2} \mathrm{O}_{5}, \mathrm{VNb}_{9} \mathrm{O}_{25}$ & 2.8 & 0.51 \\
\hline
\end{tabular}

\section{CONCLUSION}

It was shown that niobia is a selective catalyst for the oxidative dehydrogenation of propane. The activity of this material can be improved considerably by addition of molybdenum, chromium and especially vanadium, while the selectivity to propylene can be maintained at the same high level. The addition of only 1 mol\% $\mathrm{V}_{2} \mathrm{O}_{5}$ was sufficient to give an active and selective catalyst.

The results obtained from the four groups of catalysts can be explained by assuming that the active site is a vanadium ion at the surface, and that the activity and selectivity of this active site depends on the number of neighbouring vanadium and niobium ions. Neighbouring vanadium ions provide additional activity, while neighbouring niobium ions improve the selectivity. The optimal activity and selectivity are given by a site having both vanadium and niobium as neighbours ( $V-O-V^{*}-\mathrm{O}-\mathrm{Nb}$ ). When the density of vanadium atoms at the surface is too low, the chance of one vanadium site having a vanadium ion as a neighbour is small and so the catalyst will be selective but not very active. This is the case in catalysts in which the amount of vanadium added is small compared to its surface area, such as the sample calcined at $550^{\circ} \mathrm{C}$ (Table 4), sample D (Table 3) and the V0.25 Nb and one of the V $1 \mathrm{Nb}$ samples shown in Table 1. The low activity of the $\mathrm{VNb}_{9} \mathrm{O}_{25}$ phase can also be explained in this way, because it is known that the vanadium in this phase occurs in isolated tetrahedral sites at the junctions of blocks of niobium octahedra (Figure 1) [19]. The fact that the samples $\mathrm{V} 5 \mathrm{Nb}$ and $\mathrm{V} 10 \mathrm{Nb}$ (Table 1), in which $\mathrm{VNb}_{9} \mathrm{O}_{25}$ or a similar phase was also found, are active can be explained by assuming that not all the vanadium present in these catalysts is present as this phase.

An uneven distribution of vanadium can be expected on the surface of the impregnation catalyst (Table 3)'because the niobia surface will be negatively charged at the $\mathrm{pH}$ of impregnation. Metavanadate ions will not adsorb on this surface, but will instead be deposited as large crystals upon drying. Upon calcination, vanadium is known to spread over the surface, but it is unlikely that this spreading will be complete. There 


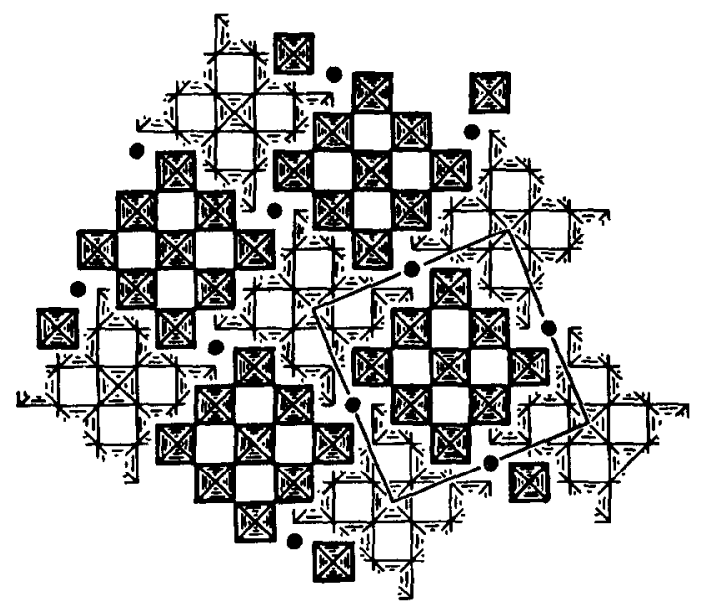

Figure 1 Structure of $\mathrm{VNb}_{9} \mathrm{O}_{25}$, which consists of blocks of 9 niobium octahedra, joined at the corners by tetrahedral vanadium (circles).

is thus a large chance that the vanadium distribution over the surface will be inhomogeneous, with patches of vanadium (having mainly vanadium atoms as neighbours) on one part of the surface and no vanadium on other parts. Most of the active sites will have vanadium atoms as neighbours; as indicated above, these will be active but not selective for oxidative dehydrogenation of propane. To a lesser extent, this is also true for the adsorption catalyst (Table 3). However, a more homogeneous distribution of vanadium at the surface can be expected in this case because the vanadium compound used is not negatively charged and can adsorb on the niobia surface. For this sample the surface concentration of vanadium appears to be above the optimum for a good selectivity.

The differences between the catalysts prepared in different ways become smaller after use. This can be explained by a redistribution of vanadium, both at the surface and in the bulk. The observation that the differences which still exist after calcination in air at $630{ }^{\circ} \mathrm{C}$ for $5 \mathrm{~h}$ disappear after use for approx. $2 \mathrm{~h}$ at $500^{\circ} \mathrm{C}$ under reaction conditions (where full oxygen conversion is reached) leads to the suggestion that for $\mathrm{V}^{4+}$ ions, (formed due to reduction when the oxygen conversion is near $100 \%$ ) are much more mobile than the $\mathrm{V}^{5+}$ ions. The bulk diffusion rate of an impurity $(\mathrm{V})$ in a matrix $\left(\mathrm{TT}-\mathrm{Nb}_{2} \mathrm{O}_{5}\right)$ depends on its oxidation state, its size and the possibility of forming compounds or solid solutions. Little is known about diffusion of vanadium ions in a niobia matrix, but it is known that an ion diffuses faster when it is smaller and has a lower oxidation state. It thus seems that $\mathrm{V}^{4+}$ diffuses faster due to its lower oxidation state despite its larger size $\left(0.63 \AA\right.$ for $V^{4+}, 0.59 \AA$ for $\left.V^{5+}\right)$. If the size of the ion is less important than its charge for bulk diffusion, it will be even more so for surface diffusion. The increased mobility of vanadium under reducing conditions also causes an increased rate of sintering. As a result, the surface areas observed after use were 
usually lower than for the fresh materials. One would not normally expect a dramatic decrease in surface area when used at temperatures below $500^{\circ} \mathrm{C}$ if the catalyst has been calcined at $630^{\circ} \mathrm{C}$ for $5 \mathrm{~h}$.

A preparation method which causes the vanadium to be distributed homogeneously at the surface and in the bulk (such as coprecipitation or the melt method) is preferred over a method which deposits vanadium only at the surface, possibly in large clusters (adsorption and especially wet impregnation). The vanadium can be reduced during use. The increased mobility caused by this reduction makes the catalyst more homogeneous, and this results in a decrease of the dependence of the performance of the catalyst on the preparation method. The melt method seems to be the most suitable preparation method to use, although it is difficult to control the surface area obtained after preparation. The selectivity obtained on the catalyst prepared by coprecipitation is marginally better.

\section{ACKNOWLEDGEMENTS}

We wish to thank Y.A. de Vries for carrying out part of the experimental work, and A. van de Berg for performing the XPS measurements. We thank Prof. I.E. Wachs (Lehigh University, Bethlehem, USA) for valuable discussions. The hydrated niobia used in the preparation of the catalysts was provided by the Niobium Products Company, Inc., USA. One of the authors (R.H.H. Smits) thanks the Dutch Foundation for Chemical Research (SON) for financial support.

\section{REFERENCES}

1 M.A. Chaar, D. Patel, M.C. Kung and H.H. Kung, J. Catal. 105 (1987) 483.

2 M.A. Chaar, D. Patel and H.H. Kung, J. Catal. 109 (1988) 463.

3 D. Patel, M.C. Kung and H.H. Kung, in M.J. Phillips and M. Ternan (eds.), Proc. $9^{\text {th }}$ International Congress on Catalysis, Calgary, Chemical Institute of Canada, Ottawa, 1988, Vol. 4, 1553.

4 K.T. Nguyen and H.H. Kung, J. Catal. 122 (1990) 415.

5 D. Patel, P.J Andersen and H.H. Kung, J. Catal. 125 (1990) 132.

6 M.C. Kung and H.H. Kung, J. Catal. 128 (1991) 287.

7 M.C. Kung and H.H. Kung, J. Catal. 134 (1992) 668.

8 O.S. Owen, M.C. Kung and H.H. Kung, Catal. Lett. 12 (1992) 45.

9 D. Siew Hew Sam, V. Soenen and J.C. Volta, J. Catal. 123 (1990) 417.

10 A. Guerrero-Ruiz, I. Rodriguez-Ramos, J.G.L. Fierro, V. Soenen, J.M. Herrmann and J.C. Volta, Stud. Surf. Sc. Catal. 72 (1992) 203.

11 A. Corma, J.M. López-Nieto, N. Paredes, M. Pérez, Y. Shen, H. Cao and S.L. Suib, Stud. Surf. Sci. Catal. 72 (1992) 213. 
12 K. Seshan, H.M. Swaan, R.H.H. Smits, J.G van Ommen and J.R.H. Ross, Stud. Surf. Sc. Catal. 55 (1990) 505.

13 R.H.H. Smits, K. Seshan, J.G. van Ommen and J.R.H. Ross, unpublished results.

14 E.M. Thorsteinson, T.P. Wilson, F.G. Young and P.H. Kasai, J. Catal. 52 (1978) 116.

15 R.H.H. Smits, K. Seshan and J.R.H Ross, J. Chem. Soc., Chem. Comm. 8 (1991) 558:

16 R.H.H. Smits, Seshan and J.R.H. Ross, Stud. Surt. Sci. Catal. 72 (1992) 221.

17 R.H.H. Smits, K. Seshan and J.R.H. Ross, to be published in S.T. Oyama and J.W. Hightower (eds.), Catalytic Selective Oxidation, ACS Symposium Series, Washington, 1992

18 R.H.H. Smits, K. Seshan, Y.A. de Vries and J.R.H. Ross, to be published

19 A.D. Wadsley, S. Andersson, in J.D. Dunitz, J.A. Ibers, Perspectives in Structural Chemistry, John Wiley \& Sons, 1970, Vol. 3, 19. 